\title{
UM OLHAR ECOLÓGICO DA FAMÍLIA SOBRE O DESENVOLVIMENTO HUMANO
}

\author{
An ecological view of the family about the \\ development of the human being
}

Elza Maria Canhetti Mondin ${ }^{1}$

\section{Resumo}

Este artigo consistiu na revisão da posição teórica da psicologia ecológica no estudo da família e suas implicações no desenvolvimento humano. Essa perspectiva recente - a ecológica contrapõe-se aos enfoques tradicionais, enfatizando os aspectos dinâmicos que apontam o contexto, a pessoa em desenvolvimento, o processo e o tempo como variáveis que se interagem reciprocamente. A ênfase no contexto influencia famílias e seu impacto sobre o desenvolvimento vem acompanhado do contexto cultural e que juntos constituemse em contextos essenciais para a compreensão do indivíduo em sua singularidade.

Palavras-chave: Família; Contexto; Perspectiva Ecológica; Desenvolvimento.

\section{Abstract}

This work is based on a review of a theoretical position of the ecological psychology in the study of families and their implications in the human development. This recent perspective - ecology opposes to tradicional focuses, emphasizing the dynamic aspects that point out the context, a person in development, the process and the epoch as variable that exercise influence upon each other. The emphasis in familiar context and its impact about development come together with the cultural context and constitute in essential contexts for the comprehension of the human beings in their particularity.

Keywords: Family; Context; Ecological Perspective; Development.

1 Doutora em Educação pela Unesp de Marília - Docente da Faculdade de Filosofia Ciências e Letras de Presidente Venceslau-SP Endereço para contato: Rua Maria Barbosa, 156 Vila Sales CEP:19400-000-Presidente Venceslau - SP

E-mail: elzamondin@hotmail.com 


\section{O Microssistema Familiar}

O presente artigo busca enfocar a família em seu funcionamento interno afetado por um sistema social mais amplo e, ao mesmo tempo, a ecologia da família afetada por pessoas e grupos que a compõem. Assim, considera-se a família como um "nicho ecológico", ${ }^{2}$ onde todos os elementos interagem reciprocamente - tendência esta registrada nas duas últimas décadas, substituindo os estudos já realizados sobre a família cujos membros eram estudados separadamente em suas relações diádicas e unidirecionais.

Embora a família seja um sistema permeável às contingências do tempo e do espaço e sofra a influência dos sistemas sociais, políticos, religiosos, ideológicos e culturais, duas funções fundamentais ao ser humano continuam a ser realizadas por ela: a primeira diz respeito à continuidade do ser humano, ao longo das gerações, uma vez que a família constitui-se em uma comunidade marcada por transições ecológicas tais como: nascimento, desenvolvimento dos filhos, decrescimento e morte; a segunda refere-se à articulação entre o indivíduo e a sociedade visando a um equilíbrio entre o "estar bem consigo próprio" e o "estar bem com os outros", ou seja, a adequação da individualização em suas dimensões afetivo-cognitiva e comportamental e a socialização. (Ribeiro, 1997).

É fundamental, assegura a autora, tentar compreender o comportamento individual inserido no seu contexto natural, a família, e esta, por sua vez, inserida em contextos sociais e culturais. Em julho de 1992, realizou-se o Congresso Internacional - "A Função Educativa da Família e Mudanças Culturais", realizado em Paris, em que os especialistas afirmaram que cabe à família preservar e transmitir os valores culturais. Diferentes concepções culturais de família foram abordadas desde a monuclear (ocidental) até as famílias patriarcais e alargadas - e em especial, destacou-se 0 papel das famílias que têm, diante de si, um futuro de pobreza. Tais famílias enfrentam também problemas culturais e educacionais, precisando de um tipo de ajuda radicalmente diversa daquela que se deve ser dada às famílias abastadas do primeiro mundo.
De acordo com o Editorial da Revista Psicologia Teoria e Pesquisa (v-16, n. 3, 2000, p.1), observa-se:

A família como um contexto dinâmico e único para crianças em desenvolvimento, tem sido negligenciada como um tópico proeminente, tanto na pesquisa sociológica quanto na psicologia do desenvolvimento. No entanto, recentemente, as questões sobre família estão sendo apontadas como uma das tendências futuras na pesquisa em psicologia.

A necessidade de pesquisa na área de família, na perspectiva do desenvolvimento humano, tem sido destacada por Kreppner (2000). Para 0 autor, o contexto familiar e seu impacto sobre 0 desenvolvimento da criança, em especial, durante os períodos de transição, são fundamentais para a psicologia contemporânea. A importância de se compreender o indivíduo no contexto familiar tem sido objeto de pesquisa, principalmente após a publicação dos trabalhos de Urie Bronfenbrenner, nas décadas de 70 e 80 . Focalizar a singularidade e a complexidade da rede relacional da "família" permite vislumbrar um novo quadro de "família" como um grupo específico em desenvolvimento, inserido em um contexto cultural também em desenvolvimento. Daí a noção de que a família e a cultura constituem contextos essenciais para a compreensão do indivíduo em sua singularidade. De acordo com Gomes (1995, p. 8), nascemos sociais e desenvolvemo-nos à mercê de um contexto de relações. Os autoconceitos que vamos construindo em nossa vida provêm das interações que se vão produzindo entre a nossa evolução biológica e as nossas vivências tanto sociais como afetivas. O desafio que se coloca na sociedade em geral e a cada família em particular consiste na busca constante de equilíbrio e na descoberta do significado da família face aos diferentes contextos de equilíbrio enfatizados por Ribeiro (1997) e que representam o desenvolvimento humano. Para Bronfenbrenner (1996, p. 5), "a perspectiva é nova em sua concepção da pessoa em desenvolvimento, do ambiente e especialmente da interação desenvolvente entre ambos". Alguns exemplos desse autor podem clarificar o conceito pouco ortodoxo de ambiente. "O ambiente ecológico é concebido

\footnotetext{
2 “Nicho ecológico" refere-se a uma expressão utilizada por Kreppner (2000).
} 
como uma série de estruturas encaixadas, uma dentro da outra, como um conjunto de bonecas russas". (p. 15). Assim, uma primeira estrutura refere-se ao ambiente imediato, contendo o indivíduo em desenvolvimento, como a família, escola, sala de aula (microssistema). A segunda estrutura ou próximo passo caracteriza-se por áreas desconhecidas, pois requer que se observem além dos ambientes simples, as relações entre eles. Tais interconexões podem ser fundamentais para o desenvolvimento, tanto quanto os eventos que ocorrem num determinado ambiente (mesossistema). $\mathrm{O}$ passo seguinte refere-se ao fato de que o desenvolvimento humano é profundamente afetado pelos eventos ocorridos em ambientes nos quais a pessoa nem sequer está presente (exossistema).

O quarto passo consiste de padrões culturais abrangentes, como as crenças, as ideologias e sistemas econômicos e políticos e que afetam indiretamente as pessoas (macrossistema).

Papalia e Olds (2000, p. 30) quando mencionam os sistemas ecológicos, afirmam:

Ao observar os sistemas que afetam os indivíduos na e além da família, a abordagem ecológica mostra a variedade de influências sobre o desenvolvimento humano. A importância relativa de cada sistema pode variar de uma sociedade para outra e de um grupo para outro dentro da mesma sociedade.

Bronfenbrenner (1979) enfatiza a falta de pesquisa a respeito do contexto, "missing context" no desenvolvimento humano. Inexiste uma estrutura teórica para a análise dos ambientes em que vive o ser humano. De fato, a tradicional exclusão da cultura revela uma dificuldade enfrentada pelas pesquisas no âmbito da psicologia do desenvolvimento. Nós, diz o autor: "Conhecemos muito mais a respeito da criança do que sobre os ambientes nos quais ela vive ou os processos através dos quais estes ambientes afetam o curso do desenvolvimento" (Bronfenbrenner, 1979, p. 844-850).

Ao tecerem críticas à exclusão da cultura, Branco e Rocha (1998), amparadas nas idéias de Bronfenbrenner, explicam que o paradigma epistemológico deve sofrer mudanças a fim de permitir a compreensão de uma realidade dinâmica, organizada de modo sistêmico e complexo, a qual é apresentada em função das inúmeras interações que com ela se estabelece, contextualizadas em um momento histórico-cultural específico que lhe confere significado especial. Em sua busca por leis universais, concluem as autoras (1998), as pesquisas tentam eliminar a dimensão contextual. Quando se inclui a cultura nas pesquisas, a neutralidade científica enfatizada pelos positivistas perde seu lugar de destaque para levar em consideração a mediação semiótica existente entre os valores e crenças do contexto sociocultural de pesquisadores e pesquisados e os próprios processos de construção do conhecimento. O enfoque sistêmico proposto por Bronfenbrenner segundo Gracia e Musitu (2000) foi consolidado nos anos 70 e é centralizado fundamentalmente na investigação ecológica do desenvolvimento humano com uma marcante ênfase contextual. Tal desenvolvimento tem lugar no contexto das relações familiares, é resultado não somente de fatores ontogenéticos, como também da interação da dotação genética da pessoa com o entorno imediato da família. Qualquer qualidade humana encontra-se profundamente imersa em um contexto ou cenário ambiental concreto, do qual a família é o principal exemplo. Concluem as autoras (2000) que as famílias não são blocos auto-suficientes do edifício social, exclusivamente responsáveis e culpadas de seus próprios destinos; pelo contrário, encontram-se profundamente influenciadas por forças poderosas sobre as quais têm um controle escasso. Para a compreensão do ecossistema familiar, Gracia e Musitu (2000), relacionam seis princípios: 1) desenvolvimento no contexto: crianças e jovens encontram-se basicamente influenciados por seu ambiente - família, amigos, companheiros de classe, vizinhos, comunidade e cultura - de forma similar os entornos onde vivem e se relacionam modelam o comportamento dos pais. Dessa forma, a habilidade de um pai para cuidar e educar com êxito uma criança não é unicamente uma questão de personalidade ou caráter, mas também uma função da comunidade e da cultura particular onde os pais e filhos vivem; 2) importância da qualidade de vida e sua relação com um entorno socialmente rico. Com base nessa formulação, os pais necessitam de uma combinação apropriada de relações formais e informais capazes de proporcionar apoio, orientação e assistência na tarefa difícil de cuidar e educar os filhos; 3) acomodação mútua pessoa/ambiente: os indivíduos e o entorno adaptam-se e ajustam-se reciprocamente. Assim, para a compreensão do comportamento humano é necessário levar em conta a interação do 
indivíduo e a situação no tempo e no espaço; 4) efeitos de segunda ordem: referem-se aos aspectos mais importantes do comportamento humano que são modelados e controlados por forças que não se encontram em contato direto com os indivíduos em interação. Assim, para fins de exemplificação, as autoras citam as relações entre os pais e suas crianças como claramente modeladas, por forças externas à família. Com freqüência, o que ocorre ao pai em seu ambiente de trabalho, afeta tanto a ele próprio como aos seus filhos, mesmo que estes nunca "ponham seus pés" nesses locais de trabalho; 5) conexões entre pessoas e contextos: as relações existentes em diferentes contextos, desenvolvidas pelos indivíduos em suas "tradições ecológicas e em díades transcontextuais", como por exemplo, a criança como estudante relaciona-se com seus pares e estes relacionamentos poderão ampliar-se com vizinhos, professores, amigos, parentes, pessoas diferentes de seus pais que transcendem a contextos distintos, persistem no tempo, fortalecem-se nas relações pais e filhos e melhoram o processo de desenvolvimento deles; 6) perspectiva do ciclo vital: sentido e significado das características pessoais e das diferentes situações podem alterar-se ao largo da evolução vital. Por exemplo, os pais confiantes e afetivos com seus filhos ainda pequenos podem experimentar dificuldades com eles em fases vitais ulteriores, como na adolescência. É preciso compreender que os papéis tanto dos pais como dos filhos mudam através das transições ecológicas e, assim, as acomodações mútuas são inevitáveis. A perspectiva sistêmica, conforme Dessen (1994), é fundamental para estudar o desenvolvimento das interações familiares. Como o sistema familiar é composto por vários subsistemas, tais como mãe-criança, pai-criança, mãe-criança-irmão(s), entre outros, e as relações são únicas, enfatiza a autora, que há necessidade de se comparar os processos pelos quais os padrões relacionais são estabelecidos e como eles mudam em cada um dos subsistemas e explica que os planejamentos de pesquisa devem levar em conta não apenas os subsistemas diádicos, mas sobretudo os triádicos e poliádicos. A abordagem sistêmica ajuda a lidar com o problema de descrever e analisar o contexto abrangente no qual a família está inserida. Suas conclusões envolvem desafios que merecem ser considerados:

A contextualização é, sem dúvida, uma variável importante, uma vez que inclui, na inves- tigação, aspectos do ambiente social e físico, relevantes para uma melhor compreensão do fenômeno. Portanto um dos nossos desafios atuais é encontrar uma maneira adequada de integrar os dados quantitativos, coletados geralmente através de observação direta, com as informações contextuais que mesmo permanecendo "escondidas", não deixam de nortear a elaboração de questões e do próprio sistema de categorias. Os pressupostos que orientam a construção das pesquisas relativas às interações e relações dentro do contexto familiar precisam ser revistos. Isto requer explorar os métodos para descrever o sistema em interação e trabalhar em projetos de pesquisa desenvolvidos por uma equipe interdisciplinar, composta por pesquisadores de áreas afins, já que a complexidade da unidade de análise aqui focalizada extrapola 0 campo da psicologia (Dessen, 1994, p. 219).

Na ausência dessa perspectiva contextual, a pesquisa contemporânea em sua grande parte caracteriza-se como o estudo do desenvolvimento fora-do-contexto. É comum observar que a maioria dos pesquisadores enfoca áreas particularizadas para estudo. E o que se conclui é que a grande dificuldade enfrentada por eles refere-se à tradicional exclusão da cultura, revela reiteradamente Bronfenbrenner (1996). O conhecimento psicológico, segundo Bennett (2000), desenvolve-se através de discussões, desafios, pesquisas por recursos diversificados e não é ainda capaz de apresentar um quadro total e coeso. Para ilustrar uma perspectiva sobre as pesquisas psicológicas encontradas, 0 autor relata uma história do século XIII, "Elefante no Escuro", cuja personagem central, um elefante, era mostrado por seu dono, nos lugarejos cujas pessoas jamais haviam visto esse animal. Ao chegarem a uma cidade à noite, quatro homens moradores desse lugar, não desejando esperar o dia seguinte para observarem o elefante, foram vê-lo no estábulo. Como não havia luz, a investigação sobre o animal deveria ser realizada no escuro. O primeiro homem ao apalpar a tromba, relatou que era semelhante à curva de um cachimbo. O segundo, ao tocar as orelhas, imaginou que fossem grandes abanadores. 0 terceiro, ao tocar as patas concluiu que fossem grandes pilares de uma construção e, finalmente, o quarto homem, ao colocar suas mãos no 
dorso do animal, aventurou-se a dizer que era uma espécie de um grande trono. Ninguém poderia formar o quadro por inteiro e da parte que cada um sentiu somente poderia ser referida em termos de coisas que eles anteriormente conheciam. O resultado dessa expedição foi uma confusão. Cada um tinha a certeza apenas de um aspecto percebido. Em termos de experiências psicológicas, cada pesquisa parece ser uma parte do quadro e é somente quando o quadro surge por inteiro é que se forma o senso de realidade. A falta de pesquisa e conhecimento sobre contextos de desenvolvimento humano (BRONFENBRENNER, 1979) impede a formação de uma estrutura teórica apropriada para analisar os ambientes em que vive o ser humano.

A questão atual, na pesquisa sobre a família, argumenta Dessen (1994), não se refere mais à bidirecionalidade da interação, mas à força relativa dos membros familiares no sistema, exigindo o enfoque da contribuição de cada um para o desenvolvimento das interações. A abordagem sistêmica enfatiza também que as pessoas fazem parte de uma rede social mais ampla e que os processos que operam em diferentes situações sociais são interdependentes. Lembra Aranha (1993, p. 23) que "mesmo as interações diádicas ocorrem em um contexto poliádico, palco da trama de relações que afeta cada interação em particular e todas as interações, influenciando-as e por elas sendo influenciado". Deverão ser consideradas, portanto, como aponta Bronfenbrenner (1996), as propriedades da pessoa e do meio ambiente como interdependentes e analisadas em termos de sistemas.

De Conti e Sperb (2001) esclarecem que a cognição e a cultura são, muitas vezes, focalizadas como processos separados. Na verdade, especificam as autoras, a Psicologia Cultural, ao contrário, visualizam-nos como processos inter-relacionados, e concluem que:

... a Psicologia Cultural deveria ter como unidade de análise as realidades ou estruturas culturalmente compartilhadas através das quais as pessoas interpretam os ambientes; ou seja, coloca que é necessánio articular o papel da pessoa que é quem interpreta a realidade através de categorias ou estruturas socialmente e culturalmente compartilhadas, na análise de qualquer fenômeno... (DE CONTI etal; 2001, p. 60).
De acordo com o paradigma da psicologia ecológica na pesquisa com famílias, Zamberlan (2003, p. 22-24) aponta alguns princípios básicos imprescindíveis ao propósito do presente trabalho: 1) refere-se à identificação da criança como um foco de análise, mas como os membros da família são seus principais e constantes agentes de cuidados, por essa razão devem ocupar um lugar central na proposição; 2) diz respeito à criança que deve ser entendida no contexto ou na ecologia de sua família. O meio físico e social constituirão as chaves para as mudanças adaptativas da criança. Desta forma, os agentes de mudança estendem-se além da família, incluindo relações com pares e outros membros da comunidade; 3) um modelo familiar é mais inclusivo do que objetivar somente a criança como foco de análise ou de tratamento. Assim, as áreas, como as de saúde, educação, serviço social através de ações coordenadas e interdependentes vêm ao encontro de esclarecimento de problemas relacionados à criança; 4) o mapeamento de uma rede extensa de relações sociais, tais como o bem-estar social, promoção da saúde integrada ao ambiente familiar objetiva oferecer apoio à família durante as transições vividas; 5) as famílias devem ser vistas em uma perspectiva saudável com capacidades de autoorganização e autofuncionalidade quando assistidas através de redes de apoio social. Finato (2003, p. 68), compartilhando com esses princípios, conclui: "O que geralmente não se analisa em profundidade é que quando se diz que, uma criança é abandonada, em sua retaguarda, está também uma família abandonada". Bronfenbrenner (1996, citado por Tornaria, 2001) enfatiza que cada criança cresce num ambiente social complexo - uma ecologia social - com seus pais, irmãos, parentes, animais de estimação, professores, vizinhos, amigos. Todos esses elementos estão inseridos num sistema social mais amplo. Assim, os pais têm empregos dos quais podem gostar ou não, podem ter amigos íntimos ou podem ser muito isolados, podem conviver com vizinhança segura ou cheia de perigos; as escolas que os filhos freqüentam podem ser excelentes ou não e os pais podem relacionar-se bem ou mal com elas. Descrever tais aspectos não basta, é necessário compreender os modos pelos quais todos os componentes desse sistema interagem reciprocamente. 


\section{Os fatores de Proteção e de Risco e o Desenvolvimento humano}

O autor aponta os fatores de proteção e de risco que colaboram, ou não, com o desenvolvimento das pessoas. Os primeiros relacionados à proteção podem ser: 1) referentes ao âmbito macrossistêmico, que desenvolve um significativo valor a respeito da família, particularmente nos momentos históricos que marcam o seu desprestígio. Esta valorização se acha presente não só nos discursos das pessoas, como também nas investigações têm mostrado que as pessoas, após o divórcio ou separação, seguem optando por formas familiares parecidas com aquelas que perderam. Por outro lado, quando uma criança não pode ser educada em sua família de origem, a sociedade busca formas substitutas que asseguram seu sadio desenvolvimento, por exemplo, a adoção. A família continua sendo, portanto, o meio ideal para 0 crescimento de crianças; 2) com relação ao exossistema, a rede de apoio que se forma na família, principalmente através dos avós, amigos e vizinhos, exercem o papel de cuidadores de criança enquanto os pais trabalham e assim amortizam ou minimizam a tensão resultante da saída do pai e da mãe no campo profissional; 3) com relação ao mesossistema, formas de apoio, tais como o estímulo de programas de cooperação entre escola e família, programas de orientação aos pais indicam que a sociedade em seus diferentes níveis é sensível à educação de crianças; 4) por último, o microssistema familiar oferece os fatores de proteção através de relações mais participantes e democráticas na família. Em contrapartida, os fatores de risco não podem ser esquecidos: 1) a coexistência de agentes de socialização, entre eles a televisão e redes de informação (internet), que podem oferecer e estimular valores e formas de vida contraditórias com as da família, como as crescentes tensões sociais e econômicas, a violência, etc.; 2) as tensões e exigências no trabalho que, para grande número de famílias, reduzem sensivelmente o tempo compartilhado com todos os elementos da família; 3) falta de coordenação e de comunicação entre os diferentes contextos em que cresce a criança, fundamentalmente entre família e escola; 4) falta de comunicação e de consistência nos valores e normas familiares, o sentimento de incompetência da parte de alguns pais para educar no mundo contemporâneo.
É importante reconhecer que os fatores ambientais de risco para o desenvolvimento raramente ocorrem de forma isolada e sim em um contexto de risco mais amplo. Como exemplo, será considerada a macrovariável pobreza que, segundo Cecconello e Koller (2000), é considerada como um tipo de ameaça constante que aumenta a vulnerabilidade da criança, pois pode causar subnutrição, privação social e desvantagem educacional. Crescer na pobreza consiste em perigo ao bemestar da criança e na limitação de suas oportunidades de desenvolvimento. A miséria econômica é uma variável de risco, que em determinadas situações não vem desacompanhada: ela permeia a relação conjugal, contribuindo para o aumento da incidência de conflitos entre os pais e produzindo um efeito direto no relacionamento desses pais e crianças. Evans (2004) adverte que as crianças pobres enfrentam iniqüidades ambientais. Elas são mais expostas às agitações familiares, violência e instabilidades. As crianças pobres vivenciam menos apoio social e seus pais são menos sensíveis e mais autoritários. Passam mais tempo frente à TV e têm menos acesso aos livros e computadores. A vizinhança de baixa renda é mais perigosa. A acumulação de múltiplos riscos ambientais em vez de um risco de exposição apenas pode ser um aspecto especialmente patogênico da infância empobrecida. Comparadas às crianças de nível econômico mais privilegiado, as crianças pobres estão desproporcionalmente expostas às adversidades física e social.

As famílias residem em um mundo físico e social e cada um deles tem documentado impactos sobre o desenvolvimento humano. Muitas condições físicas e psicossociais adversas não ocorrem isoladamente e a qualidade das condições físicas e sociais de vida não é aleatoriamente distribuída na população. As pesquisas de Ackerman, Brown e Izard (2003) enfocam que as desvantagens econômicas estão associadas aos vários fatores que colocam em perigo a adaptação e 0 desempenho das crianças no contexto escolar. Assim, é possível concluir que o empobrecimento cognitivo do contexto familiar reduz a habilidade verbal e outros desempenhos de ordem intelectual. A instabilidade da vida familiar e conflitos na relação familiares geram dificuldades no ajustamento social da criança quando vivencia o novo ambiente: o escolar. E, finalmente, os problemas comportamentais presentes no início da escolaridade 
tendem a persistir nos anos ulteriores. Ackerman et al. (2003) concluíram, com base em suas pesquisas que: 1) as famílias instáveis economicamente mudam-se mais freqüentemente de residências; 2) as famílias recasadas e de pais solteiros não podem ser ignoradas, visto que suas crianças estão constantemente enfrentando transições nada suaves; 3) os períodos de instabilidade parecem funcionar como geradores e estimuladores de problemas comportamentais em crianças, que deixariam de existir nos períodos de relativa estabilidade. Similarmente, a falta desses períodos estáveis, onde altos níveis de pais desajustados e disciplina rígida que caracterizam a persistência dos problemas comportamentais dos filhos funcionarão como mantenedores deste contexto. As pesquisas desenvolvidas por Vandenplas-Holper, Paternostre-Verdickt e Seynhaeve (2002) revelam que o status socioeconômico dos pais, tais como: nível de escolaridade, a renda, a profissão, as condições de moradia, está fortemente relacionado aos valores que consideram importantes para a educação de seus filhos, e alertam que:

... os pais que pertencem ao status socioeconômico menos favorecido valorizam particularmente a obediência a atenção e a higiene, os que pertencem aos status mais favorecidos valorizam particularmente a curiosidade e a autonomia. (Vandenplas - Holper e tal, 2002, p. 280)

Os maiores impactos dentre as mudanças estruturais ocorridas nestas ultimas décadas no contexto familiar dizem respeito, segundo Demo (1992), ao divórcio, ao emprego da mãe fora do lar, resultando na ausência do pai e da mãe grande parte do dia, ao pai ou mãe responsável pela criação dos filhos (lares com pais solteiros). Existe, indiscutivelmente, uma erosão geral do comprometimento dos pais e apoio às crianças. Entretanto, argumenta o autor que as conseqüências da estrutura familiar surgidas e relacionadas nos parágrafos anteriores têm sido acentuadamente exageradas e que os pesquisadores precisam investigar os processos que influenciam mais diretamente as crianças, especialmente as dificuldades econômicas e altos níveis de conflitos familiares. A literatura popular freqüentemente responsabiliza a família pelas altas taxas de atividade sexual dos adolescentes, gravidez precoce, delinqüência e uso de álcool e drogas, citando recorrentemente os baixos níveis de interações pais-criança e alto nível de conflitos familiares (lares destruídos). Ao delinear o panorama da família na atualidade, Demo (1992) revela que o bem-estar das crianças americanas tem declinado desde a década de 60 . Entre 1960 e 1980, os escores de desempenho acadêmico caíram, enquanto as taxas de delinqüência, o aborto, o álcool e a droga estão crescendo dramaticamente. Durante este mesmo período, observam-se a participação feminina no mercado de trabalho, o divórcio com altas taxas de crescimento e uma profunda erosão dos laços entre pais e filhos. Existem evidências, entretanto, que 0 emprego materno e o divórcio não podem ser considerados como causas determinantes da destruição do equilíbrio no contexto familiar, embora numerosos estudos tenham revelado, primeiramente, que os pais trabalhando fora e em tempo integral passam consideravelmente menos tempo com suas crianças, comparados aos casais tradicionais em que somente o pai exerce função fora do lar. Em segundo lugar, que a dissolução dos casamentos e possíveis reconstruções rompem os laços entre pais e filhos e causam a curto prazo problemas emocionais e comportamentais às crianças. É verdade que, adverte Demo (1992), as famílias de pais solteiros, cuja maioria é de mulheres, estão menos envolvidas com os trabalhos escolares de suas crianças e encontram maiores dificuldades em supervisioná-las e discipliná-las. Mas, a despeito das evidências que se acumulam com relação às conseqüências negativas já mencionadas, lembra 0 autor que as pesquisas sobre família continuam a ser dirigidas pelas noções tradicionais de família normal e família não normal.

\section{As Famílias na Contemporaneidade}

Enquanto o novo século começa a se desdobrar, as famílias, de acordo com Kaslow (2001), estão experimentando grande turbulência e vivendo em circunstâncias tumultuadas. Quando se pensa nas famílias contemporâneas, é necessário observar que a tradicional família nuclear, formada de duas gerações unidas pelo casamento e tendo seus próprios filhos biológicos, predominante nas décadas de 60 e 70, deu lugar a uma variada gama de estilos familiares. A realidade é esta: a família mudou e por essa razão é necessário reconceituá-la no sentindo de incluir todas as 
formas existentes e gerar protótipos saudáveis de cada uma. Uma pesquisa desenvolvida por Jaffee, Moffitt, Caspi e Taylor (2003) evidenciou a existência de efeitos salutares em crianças que convivem com seus pais biológicos, entretanto, isso dependerá da qualidade dos cuidados que os pais podem oferecer a elas. Quando os pais engajamse em altos níveis de comportamentos anti-sociais, quanto mais tempo conviverem com suas crianças, maiores problemas de conduta estas apresentarão. O casamento, concluem os autores, pode não ser a resposta para os problemas encontrados por algumas crianças que convivem em famílias de pais solteiros ou com pais ausentes. Jadue (2003) explica que os filhos provenientes de famílias com altos níveis de conflito correm o risco de não aprenderem as habilidades sociais como a negociação e o compromisso. Embora a separação dos pais seja dolorosa, os filhos que permanecem em uma família intacta com tensões estão menos adaptados do que os que fazem frente à transição dolorosa a uma família monoparental e que vivem com menos tensões e conflitos. Em geral, as crianças crescem sem problemas de ajustamento quando têm uma boa relação com um só pai e/ou mãe, do que quando crescem em um lar com os pais (mãe e pai) que se caracteriza pela discórdia e descontentamento. Portanto, um pai inacessível, hostil, pode causar maiores danos que um pai ausente. Os anos iniciais do novo milênio revelam que as famílias refletem os problemas dos contextos mais amplos nos quais os seus membros vivem. Muitas se encontram contaminadas pelo estresse causado pelas mudanças políticas e sociais. Uma outra mudança significativa de nossos tempos refere-se ao relacionamento entre homens e mulheres e que vem ocorrendo desde os anos sessenta. Redefinições de homem e mulher e as reconstruções de masculinidade e feminilidade como entidades separadas e em conexão de um para outro têm se desenvolvido lentamente. Lamentavelmente, Kaslow (2001) informa que a quantidade e a severidade da violência dentro da família parece estar crescendo, conforme relatos e publicações em todas as partes do mundo. O lar, anteriormente retratado como um lugar seguro, um refúgio de paz, é, muitas vezes, o lugar em que esposas e crianças são violentadas e maltratadas. Em países atingidos pela fome, desemprego, profunda frustração e desespero podem transformar-se em ações violentas em direção aos membros familiares mais vul- neráveis. Kristensen, Silveira Lima, Ferlin, Flores e Hackmann (2003) informam que os atos violentos não podem ser espontâneos, mas precisam ser aprendidos lentamente e necessitam de modelos que os pratiquem (família, sociedade ou ídolos) que demonstrem tipos de ações que são recompensadoras ou passíveis de punição. Castro, Melo e Silvares (2003) enfatizam o processo de socialização que é inicialmente desenvolvido no contato com os pais em que a criança aprende uma série de habilidades motoras, lingüísticas e afetivas, necessárias para a orientação em seu ambiente físico e social. Tais habilidades passarão por sucessivas transformações à medida que a criança ingressa em novos grupos sociais com seus desafios e exigências. Assim, concluem Castro et al. (2003) que o comportamento dos pais e altos níveis de elementos estressores na família são freqüentemente associados com perturbações em crianças com prognósticos de um curso fácil no decorre da infância. Os contextos de adversidade ambiental, segundo Ferreira e Marturano (2002), geram com freqüência o desenvolvimento de comportamentos externalizantes (comportamentos marcados por hiperatividade, impulsividade, oposição, agressão, desafio e manifestações anti-sociais) e as variáveis familiares podem contribuir para a persistência dos problemas da fase pré-escolar à escolar. Nas famílias de crianças com problemas, esclarecem as autoras, o que sobressai são as interações negativas, provavelmente relacionadas às manifestações externalizantes da criança indicando um estilo parental reativo. Enquanto que os pais de crianças sem problemas de comportamento parecem ter uma abordagem proativa: eles organizam e planejam mais o cotidiano dos filhos, estão mais disponíveis para ajudá-los e se ocupam mais com providências relacionadas às atividades de estudo e lazer e se preocupam com a segurança deles. Lohr (2003, p. 477) esclarece que:

Classes comportamentais como assertividade, solução de problemas, empatia, as quais compõem o rol das habilidades sociais, são por sua vez, desenvolvidas na interação com 0 outro. Assim, tanto as habilidades sociais são fundamentais para o convívio entre pessoas, como o convívio entre pessoas é essencial para que as habilidades sociais se desenvolvam. Considerando que os pais constituem o primeiro núcleo social da criança, é natural que a figura dos pais e as práticas parentais 
adotadas tenham grande influência no processo de construção das habilidades sociais da criança. Assim, estaremos analisando a relação entre práticas parentais e o desenvolvimento das habilidades sociais.

É necessário esclarecer aos pais que os comportamentos valorizados pela família e esperados que sejam apresentados pela criança devem ser ensinados. Além disso, é importante acrescentar que o ser humano vive em comunidade, esse comportar-se deve, obviamente, levar em conta uma importante parte do ambiente: as outras pessoas. Gomide (2001) explica que as diferentes maneiras utilizadas pelos pais no cuidado dos filhos podem estar correlacionadas tanto com o desenvolvimento saudável da criança como podem vincular-se ao desenvolvimento de comportamentos anti-sociais. Por exemplo, a monitoria aparentemente é um poderoso inibidor do desenvolvimento de condutas anti-sociais em crianças e adolescentes; já a negligência e o espancamento apresentam alta co-relação com comportamentos infratores. $\mathrm{O}$ abuso físico, caracterizado por maus tratos e/ ou espancamento, aumenta poderosamente as chances de a criança desenvolver repertório agressivo ou infrator. A criança espancada pode vir a acreditar que é uma pessoa má e, portanto, merecedora desta ação. Com base nesta autopercepção, seus comportamentos inadequados, infratores, agressivos - anti-sociais - podem tornar-se manifestos, visto que ela aprende que "seres maus apresentam comportamentos maus". A punição, nas palavras de Sidman (1995), pode produzir a paz que os pais desesperados necessitam, às custas dos inevitáveis efeitos colaterais - mas não oferece à criança qualquer caminho alternativo de ação, nenhum caminho para adaptar-se construtivamente. (Gomide, 2001, p. 38).

É importante lembrar que, além das regras, os comportamentos dos pais são observados e copiados pelas suas crianças. De acordo com Caballo (2001), as crianças observam como os pais interagem com elas e com as outras pessoas e aprendem seu estilo. Tanto os comportamentos verbais, (temas de conversação, fazer perguntas, produzir informações), como os comportamentos não-verbais (sorrisos, entonação de voz, distância interpessoal) podem ser aprendidos pela modelação durante a infância. Este período, afirma o autor, parece ser responsável, em alto grau pelo de- senvolvimento futuro. Na família, o comportamento dos pais, alertam Saldaña, Del Prette e Del Prette (2002), torna mais provável o comportamento de filhos, através da aprendizagem observacional, formando-se uma cadeia de transmissão de regras de estilo de comportamento de pais para filhos.

É evidente que, no convívio diário, ensinam Alvarenga e Piccinini (2001), os pais procuram direcionar o comportamento de suas crianças no sentido de obedecer a certos princípios morais e adquirir uma ampla gama de comportamentos que garantam independência, autonomia e responsabilidade, para que mais tarde possam desempenhar adequadamente seu papel social. Por outro lado, também se esforçam para reduzir ou suprimir comportamentos que sejam considerados socialmente inadequados.

\section{Conclusões}

As pesquisas direcionadas ao tema "família" na atualidade vêm apresentando conteúdos ecológicos de desenvolvimento, nos quais existem aspectos fundamentais, diversos dos da psicologia clínica (diádica) e científica (experimental) realizados até então. O enfoque ecológico do desenvolvimento privilegia os aspectos saudáveis do desenvolvimento, os estudos realizados em ambientes naturais e a análise da participação da pessoa enfocada no maior número possível de ambientes e em contato com diferentes pessoas - díades, tríades, etc. Configura-se atualmente um novo Zeitgeist neste campo, visto que os processos psicológicos e sua relação com as multideterminações ambientais, sem negligenciar a importância dos fatores biológicos no decorrer do desenvolvimento, são valorizados. A pessoa em desenvolvimento atua e muda o ambiente. Esta ênfase no contexto do desenvolvimento, que encontra repercussões na abordagem ecológica de Bronfenbrenner, contrasta com as demais teorias desenvolvimentais que retratam o ser humano isolado de seu contexto. Este paradigma epistemológico deve sofrer mudanças com o objetivo de permitir a compreensão de uma realidade dinâmica, sistêmica e complexa, a qual é apresentada em função das interações que com ela se estabelece, contextualizadas em um momento histórico-cultural específico que lhe confere significado especial. A conclusão deste trabalho é a de que todo seu conteúdo 
está longe de ser a palavra final. Novas pesquisas poderão surgir a partir deste e que contribuirão para o surgimento de novos conhecimentos sobre o desenvolvimento humano.

\section{Referências}

Ackerman, B.P., Brow, E. \& Izard, C.E. Continuity and change in levels of externalizing behavior in school of children from economically disadvantaged families. Child Development, 74, (3), 694-709.

Alvarenga, P., \& Piccinini, C. (2001). Práticas educativas maternas e problemas de comportamento em pré-escolares. Psicologia: Reflexão e crítica, 14, (3), 449-460.

Branco, A., \& Rocha, R.F. A questão da metodologia na investigação científica do desenvolvimento humano. Psicologia: Teoria e pesquisa 14, (3), 251-258.

Bronfenbrenner, V. (1996). A ecologia do desenvolvimento humano: Experimentos naturais e planejados. Porto Alegre: Artes médicas.

Bronfenbrenner, V. Context of child rearing. Problems and Prospects. Americam Psychologist, 34, (10), 844-850.

Caballo, V. E (2001). El papel de las habilidades sociales en el desarrollo de las relaciones interpersonales. In, Zamignani, D.R. (org.) Sobre comportamento e cognição - aplicação da análise do comportamento e da terapia cognitivo comportamental no hospital geral e nos transtornos psiquiátricos (Vol, 3, pp 233-254). Santo André: ESETEC.

Castro, R.E.F. de Melo, M.H.S. \& Silvares, E.F.M. (2003). O julgamento de pares de crianças com dificuldades interativas após um modelo ampliado de intervenção. Psicologia; Reflexão e crítica. 16, (2), 309-318.

Ceconello, A.M., \& Koller, S.H. (2000). Competência social e empatia: um estudo sobre resiliência com crianças em situação de pobreza. Estudos de psicologia (Natal). 5, (1), 71-93.

Conti, L., \& Sperb, T.M. (2001). O brinquedo de pré-escolares: Um espaço de ressignificação cultu- ral. Psicologia: Teoria e pesquisa. 17, (1), 59 67.

Evans, G.W. (2004). The enviroment of childwood poverty. American Psychologist. 59, (2), 77 92.

Demo, D.H.; Parent-child relations: Assessing recent changes. Journal of marriage and the familiy. 54, $104-117$.

Dessen, M.A. (1994). Interações e relações no contexto familiar: questões teóricas e metodológicas. Psicologia: Teoria e prática. 10, (2), 213-220.

Dessen, M.A., \& Silvaneto, N.A. Psicologia: Teoria e pesquisa. Editorial. Questões de família e desenvolvimento e a prática de pesquisa 16, (3), $0-0$.

Ferreira, M.C.T., \& Marturano, E.M. (2002). Ambiente familiar e os problemas do comportamento apresentados por crianças com baixo desempenho escolar. Psicologia: Reflexão e crítica. 15, (1), 35-44.

Finato, M.S.S. (2003). O abandono e a institucionalização. In Zamberlan, M.A.T.(org) Psicologia e intervenção. Modelos de intervenção na infância e na adolescência. Londrina: Eduel.

Gomes-Pedro.(1995) J. Desenvolvimento, identidade e educação - perspectivas para o bebé XXI, in Gomes-Pedro, J., \& Patrício, M.F. (coord.) Bebé XXI Crianças e família na viagem do século. (pp. 323). Lisboa, Fundação Calouste Gulbenkian.

Gomide, P.I. Efeitos das práticas educativas no desenvolvimento do comportamento anti-social. In Marinho, M.L, \& Caballo, V.E. (orgs) Psicologia clínica e da saúde. Londrina: U.E.L

Gracia, E.F., \& Musitu, G.O. (2000) Psicologia sosial de la família Temas de Psicología. Barcelona: Paidós.

Jadue, G.J.(2003). Transformaciones familiares in Chile: Riesgo creciente para el desarrollo emocional, psicosocial y la education de los hijos. Estudios pedagógicos. 29, 115 -126.

Jafes, S.R., Maffitt, T.E., CASPI. A., \& TAYLOR (2003). A. Life with (or without) father: The benefits of living with two biological parents depend on the father's antisocial behavior. Child development. 74, (1), $107-126$. 
KASLOW, F. (2001). Families and family psychology at the millennium, American Psychologist. 56, (1), 37 - 46.

Kreppner, K. (2000). The child and the family: Interdependence in developmental pathways, Psicologia: Teoria e pesquisa. 16, (1), 11-22.

Kristensen, C.H., Lima, J.S., Ferlin, M., Flores, R.Z., \& Hackmann, P. (2003). Fatores etiológicos da agressão física: uma revisão teórica. Estudos de psicologia (Natal). 8, (1), 175-184.

Lohr, S.S.(2003). Estilos parentais e desenvolvimento de habilidades sociais. In Brandão, M.Z.S., Silva, F. B., Ingerman, Y.K., Moura, C.B., Silva, V.M., \& Oliane, S.M. Sobre Comportamento e cognição. A história e os avanços, a seleção por conseqüência em ação. (Vol 11, pp.476-482). Santo André

Lloud, P. B. (2000). Children with emotional and behaviour difficulties and their parents. Emotional and behavioural difficulties: a peer reviewed journal. 5, (3), 13-17.

Papalia, D.E., \& Olds, S.W. (20000). Desenvolvimento humano. Porto Alegre: Artmed.

Ribeiro, M.T. (1997). Psicologia da família: A emergência de uma nova disciplina in MARCHAND, H.,
\& REBELO PINTO, H. (eds) Família: Contributos da psicologia e das ciências da educação. Lisboa: Educa.

Saldaña, M.R.R., Del Prette, A., \& Del Prette, Z.A.P (2002). A importância da teoria de aprendizagem social na constituição da área de treinamento de QUEIROZ, P.P., SCOZ. M.C. Sobre Comportamento e Cognição - Contribuições para a construção da teoria do comportamento: $p, 269$ 283. Santo André: Esetec,.

Vandenplas-Holper, C., Patermostre-Verdckt, L., \& Seynhaeve, I. (2002). Lês stratégies directives et lês stratégies de distanciation des mères dans um jeu de construction et de faire-semblant Enfance. (3), 277-289.

Zamberlan, M.A.T. (2003). Psicologia e Prevenção. Modelos de intervenção na infância e na adolescência. Londrina: Eduel.
Recebido em/ received in: 28/03/2005 Aprovado em/ approved in: 06/04/2005 